\title{
Presence of foam cells containing oxidised low density lipoprotein in the synovial membrane from patients with rheumatoid arthritis
}

\author{
Paul G Winyard, Franz Tatzber, Hermann Esterbauer, Michele L Kus, David R Blake, \\ Christopher J Morris
}

\begin{abstract}
Objective-Increased concentrations of lipid peroxidation products have been described in the serum and synovial fluid from patients with rheumatoid arthritis. A large proportion of the unsaturated lipids in human extracellular fluids is a component of low density lipoprotein (LDL). The oxidative modification of LDL, and its subsequent uptake by macrophages, has been implicated in the pathogenesis of atherosclerosis, but not of rheumatoid arthritis. This study aimed to assess whether oxidatively modified LDL was present in the rheumatoid synovium. Methods-A polyclonal antiserum raised in rabbits against oxidised LDL (o-LDL) was used to perform an immunohistochemical study of a series of synovial biopsy specimens from patients with rheumatoid arthritis.

Results-Collections of positively stained macrophages, arranged in a linear fashion and with the morphological characteristics of foam cells-that is, 'fatty streaks', were identified around blood vessels within the intimal connective tissue. In addition, scattered, positively stained foam cells were present in association with deposits of fibrin. These staining patterns were absent from control synovial membranes (traumatic knee injuries).

Conclusions-The findings in all rheumatoid patients studied suggest that atherosclerosis and rheumatoid arthritis have analogous pathogenetic features.
\end{abstract}

(Ann Rheum Dis 1993; 52: 677-680)

Many workers have suggested that the microvasculature has a pathogenetic role in rheumatoid arthritis, ${ }^{1}$ and some of the histopathological changes in rheumatoid synovitis are similar to those noted adjacent to atherosclerotic plaques ${ }^{1}$ - for example, accumulation of mononuclear cells at the extraluminal surface of the vascular endothelium and in the adventitia, together with immune complex deposition.

Recently, important advances have been made in understanding atherogenesis. ${ }^{2}$ In vitro the polyunsaturated fatty acids in plasma low density lipoproteins (LDLs) can be oxidised by endothelial cells and macrophages. Such oxidised LDL (o-LDL) has chemotactic properties for monocytes and is cytotoxic to endothelial and smooth muscle cells. Peroxidation products of polyunsaturated fatty acids in LDL, which include malondialdehyde and 4-hydroxynonenal, modify the apolipoprotein B moiety of LDL preventing its removal by the classical receptor pathway. ${ }^{3}$ The o-LDL is, however, recognised and internalised by the scavenger receptors of macrophages, which then become lipid-laden foam cells. ${ }^{3}$ The formation of foam cells is an early event in the genesis of atherosclerotic plaques, and o-LDL has been shown to be present in these plaques by immunostaining with antibodies raised against o-LDL. ${ }^{4}$

End products of lipid peroxidation, such as 4-hydroxynonenal, have been detected in rheumatoid synovial fluid. ${ }^{5}$ The inflamed synovium is also rich in macrophages, has extensive iron deposits ${ }^{6}$ capable of catalysing lipid peroxidation, and contains plasma proteins, including lipoproteins derived from trauma induced microbleeding. Furthermore, in rheumatoid synovial fluid the concentration of vitamin $\mathrm{E}$, which protects LDL against oxidation, is depressed. ${ }^{7}$ We therefore suggest that o-LDL formation takes place in the inflamed joint, the cytotoxic properties of o-LDL contributing to the inflammatory response. On this basis, we raised a polyclonal antibody and looked for o-LDL in the rheumatoid synovium using immunohistochemistry.

\section{Methods}

ISOLATION AND OXIDATIVE MODIFICATION OF LDL

Low density lipoprotein was isolated from healthy donors by $\mathrm{KBr}$ density step gradient ultracentrifugation. EDTA was present throughout all the steps of isolation. The isolated LDL $(250 \mu \mathrm{g} / \mathrm{ml})$ was then desalted and incubated with $\mathrm{CuSO}_{4}(1.66 \mu \mathrm{mol} / \mathrm{l})$ in oxygen saturated, phosphate buffered saline (PBS) until completely converted to o-LDL (at least five hours). ${ }^{8}$ The oxidation process was monitored by the formation of conjugated dienes (absorbance at $234 \mathrm{~nm}$ ). ${ }^{8}$ 
PREPARATION OF ANTISERUM

Rabbits were immunised five times with o-LDL at intervals of at least two weeks. The first two injections were given subcutaneously with complete Freund's adjuvant and incomplete Freund's adjuvant, respectively. Two further boosts were given subcutaneously without adjuvant. At least one boost was administered intravenously without adjuvant. Three weeks after the last boost the animals were killed by exsanguination under anaesthesia. Serum was obtained by centrifugation and stored at $-20^{\circ} \mathrm{C}$ until use.

ANTISERUM TITRATION AND CROSS REACTIVITY Polystyrene microtitre plates (Beckton Dickinson ProBind 3915) were coated with $250 \mu \mathrm{lo}$-LDL $(10 \mu \mathrm{g} / \mathrm{ml})$ in PBS (pH 8.0) for at least 24 hours at $4^{\circ} \mathrm{C}$. For titration, the antisera were diluted in PBS ( $\mathrm{pH} \mathrm{7.4)}$ containing $2 \%$ protein to block non-specific binding sites on the plates. Dilutions were performed logarithmically from $1: 10$ to $1: 10^{6}$. Normal rabbit serum was used as a control. Non-specific binding of the antiserum was tested on the same plates without o-LDL coating. Before starting the assay the coating solution was removed and the plate was washed five times with washing buffer (PBS, pH $7 \cdot 4$ containing $0.5 \%$ Tween 20 ). Each dilution of antiserum $(200 \mu \mathrm{l})$ was pipetted into the wells of the polystyrene plates in duplicate. The plates were then incubated for two hours at $37^{\circ} \mathrm{C}$. After another washing step as described before, $150 \mu$ l of goat antirabbit antiserum labelled with peroxidase (BioMakor, Israel) in a dilution of 1:2000 was added to each well and again incubated for one hour at room temperature. After washing the plate once more with washing buffer (four times) and additionally (one time) with developing buffer (phosphate-citrate buffer, $\mathrm{pH} 5 \cdot 0$ ) the enzymesubstrate reaction was started by addition of $100 \mu \mathrm{l}$ of developing reagent (40 mg 1,2-phenyl-

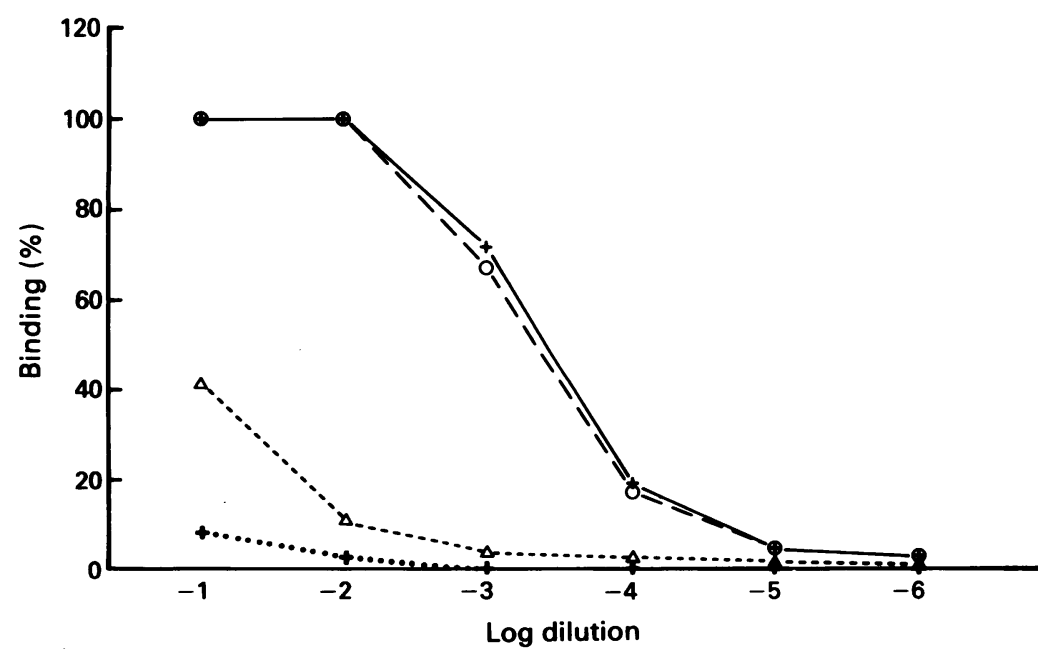

Figure 1 Antiserum titration and cross reactivity. Concentration-response curves show the binding of antiserum, raised by immunisation of rabbits with human oxidised low density lipoprotein (o-LDL), to immobilised human o-LDL. (+- + binding of rabbit antihuman o-LDL antiserum (anti-o-LDL) alone; $(\triangle---\triangle)$ binding of anti-o-LDL in the presence of o- $L D L(10 \mu \mathrm{g} / \mathrm{ml})$ as a competitor; $(\mathrm{O}--\mathrm{O})$ binding of anti-o-LDL in the presence of native $L D L(50 \mu \mathrm{g} / \mathrm{ml}) ;(+\cdots+)$ binding of anti-o-LDL in the presence of native $L D L(500 \mu \mathrm{g} / \mathrm{ml})$. enediamine and $20 \mu \mathrm{l}$ of $30 \%$ hydrogen peroxide (Merck) in $50 \mathrm{ml}$ of developing buffer). Absorption values were read in a microplate reader at $492 \mathrm{~nm}$. The antiserum titre was expressed as the reciprocal of that dilution which gave $50 \%$ of the initial absorbance.

IMMUNOHISTOCHEMISTRY

Synovial membranes from the knees of six patients with definite rheumatoid arthritis (American Rheumatism Association criteria) were obtained at operation. As controls, synovial membranes from the knees of three patients with traumatic knee injuries were obtained. Small pieces were briefly fixed in $10 \%$ buffered formalin at $4^{\circ} \mathrm{C}$ and embedded in paraffin wax by standard procedures. Thin (5 $\mu \mathrm{m}$ ) sections were cut, rehydrated, and stained with the above polyclonal rabbit antibody against human o-LDL, using an avidin-biotin-peroxidase technique (Dako). Light counterstaining with Harris's haematoxylin was performed

\section{Results}

As shown in fig 1 , immunisation of rabbits with o-LDL yielded antisera with high reactivity to o-LDL. Titres were approximately equal for three different antiserum preparations (data not shown), being about $5 \times 10^{4}$ when expressed as the reciprocal of that dilution which gave $50 \%$ of the initial absorbance. If human o-LDL was added as a competitor at concentrations of up to $50 \mu \mathrm{g} / \mathrm{ml}$, the binding of the antiserum to the immobilised o-LDL was inhibited in a dose-dependent manner, with o-LDL at $10 \mu \mathrm{g} / \mathrm{ml}$ giving almost complete blocking when the antiserum dilution was $1: 1000$ (fig 1). In contrast, addition of up to $50 \mu \mathrm{g} / \mathrm{ml}$ native LDL resulted in no significant blocking of the binding of the antiserum, and a large excess of native LDL $(500 \mu \mathrm{g} / \mathrm{ml})$ was required to completely block binding at a dilution of 1:1000 (fig 1). To minimise potential tissue cross reactivity further the neat antiserum was incubated overnight with native LDL $(500 \mu \mathrm{g} / \mathrm{ml})$, the immune complexes of which were removed by centrifugation $(10000 \mathrm{~g})$ before the antiserum was used in immunohistochemical studies at a dilution of 1:500.

Positive staining for o-LDL was found in the synovia of all six patients and fell into the following distinct patterns: (1) Positive staining of perivascular macrophages within the intima (figs $2 \mathrm{~A}$ and B). This was frequently associated with collections of positively stained macrophages arranged in a linear fashion (fig $2 \mathrm{C}$ ). These macrophages had the morphological characteristics of foam cells. (2) Intense staining of deep intimal and subintimal connective tissue. Scattered positively stained foamy macrophages were associated with deposits of fibrin (fig 2D). (3) Staining of fibrous connective tissue in the proximity of blood vessels within the intima (fig $2 \mathrm{E}$ ). (4) Staining of intimal cells at the joint space interface (fig $2 \mathrm{~F}$ ). This seemed to be 
A

C

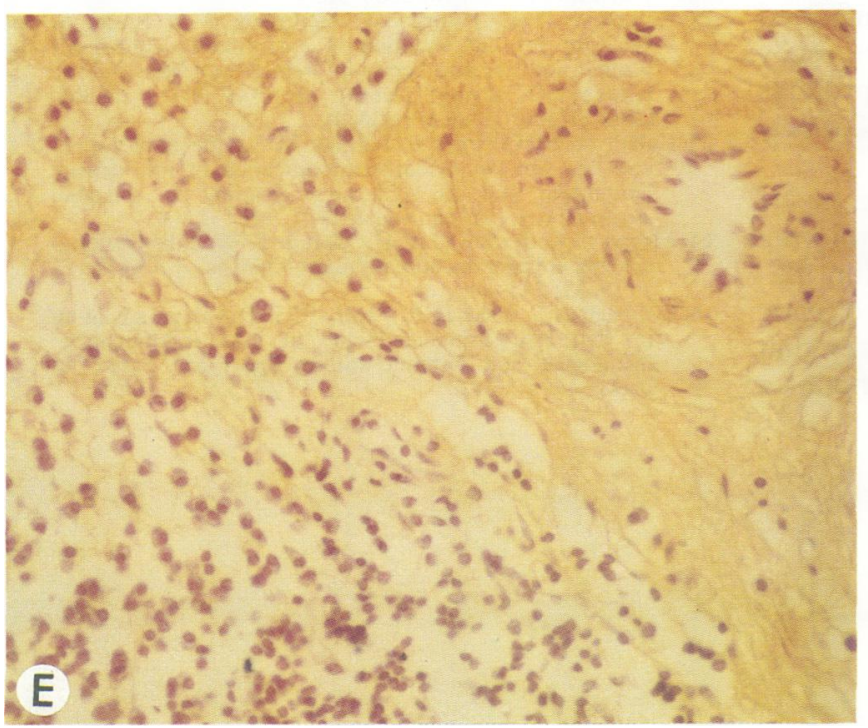

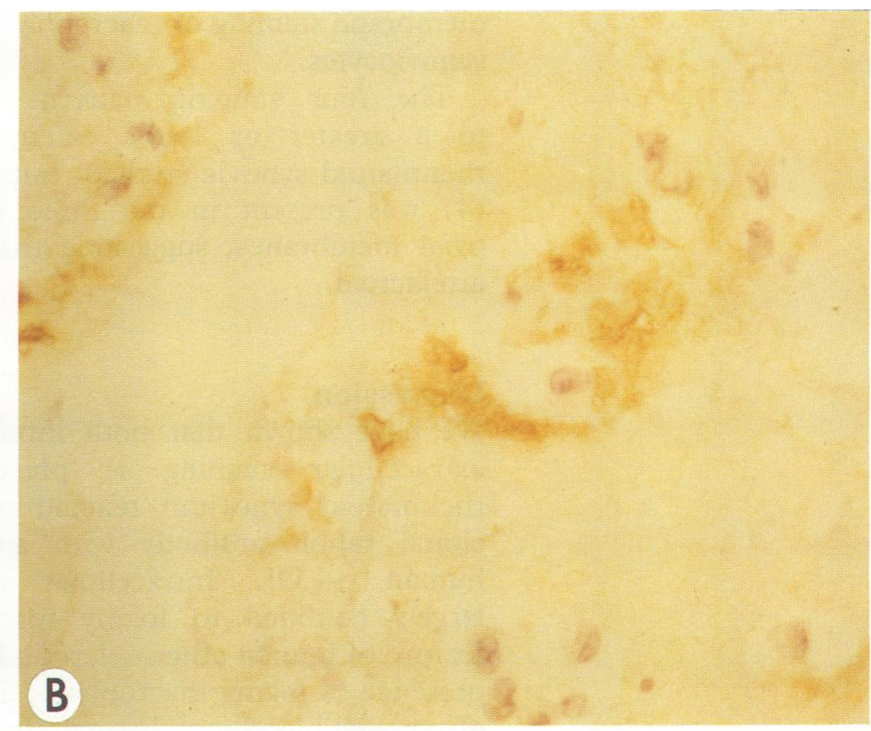

孛

꼰

$\frac{\sqrt{5}}{3}$
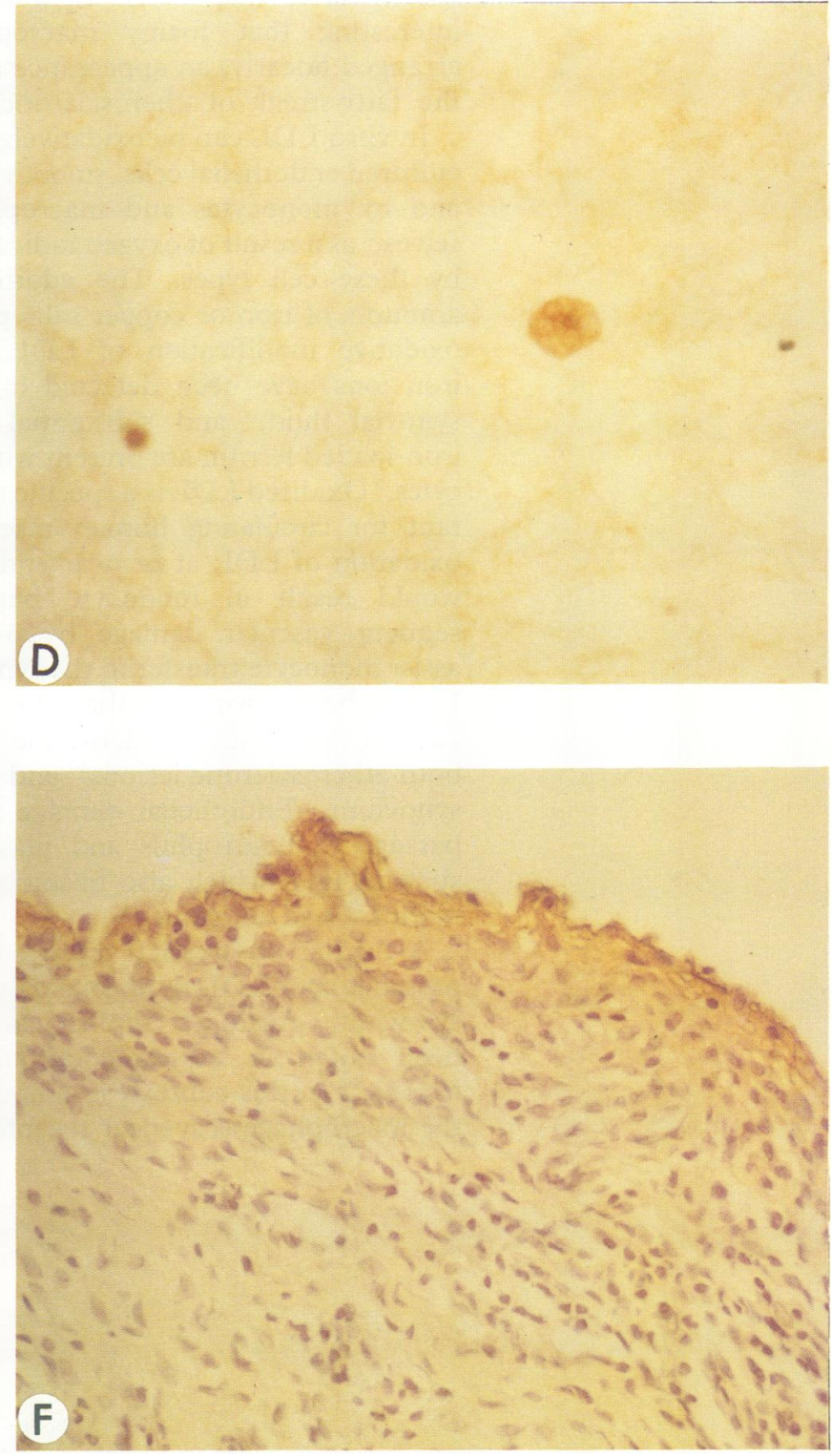

Figure 2 Immunohistochemical staining for oxidised low density lipoprotein (o-LDL) within human knee joint synovial membrane sections. Nuclei were counterstained with haematoxylin. Rabbit polyclonal antibody against o-LDL (dilution 1:500; avidin-biotin-horseradish peroxidase technique). (A) Positive staining of perivascular macrophages from a patient with rheumatoid arthritis; (B) higher magnification of a single vessel from $A$ showing the foamy nature of the perivascular macrophages; (C) extensive staining of foamy macrophages comparable with fatty streak development in a second patient with rheumatoid arthritis; (D) high magnification of a single positively staining foam cell within a fibrin clot in the synovium of a third rheumatoid patient; with rheumatoid arthritis; (D) high magnification of a single positively staining foam cell within a fibrin clot in the synovium of a third rheumatoid patient;
(E) synovium from the second patient, showing positively stained fibrous tissue surrounding a synovial blood vessel. The area is extensively infiltrated with plasma cells and lymphocytes; (F) synovium from the second patient, showing positive staining of intimal cells at the joint space interface. This staining pattern was also present in control tissue. 
membrane staining of macrophage-like type A synoviocytes.

The four staining patterns were found to a greater or lesser extent in all the rheumatoid synovia studied, but only pattern (4) was present in the three control synovial membranes, suggesting that it may be artefactual.

\section{Discussion}

We have shown that both intracellular and extracellular staining is present in the rheumatoid synovium reacted with a polyclonal rabbit antibody with specificity for human o-LDL. Intracellular staining was largely confined to foamy macrophages, a feature of human atherosclerotic lesions. ${ }^{4}$ The presence of foamy macrophages in the region of synovial blood vessels suggests that they are derived from blood, the o-LDL being ingested shortly after diapedesis. It was particularly interesting that foamy macrophages were arranged linearly, an appearance analogous to the 'fatty streak' of atherosclerotic lesions. ${ }^{4}$

In vitro LDL can be oxidatively modified by cultured endothelial cells, smooth muscle cells, and by monocytes and macrophages themselves, ${ }^{2}$ as a result of oxygen radical production by these cell types. The addition of trace amounts of iron or copper salts promotes the oxidative modification of LDL. ${ }^{2}$ Catalytic iron ions have been detected in rheumatoid synovial fluid, ${ }^{6}$ and substantial deposits of iron-loaded ferritin are present within synoviocytes. ${ }^{6}$ Oxidised LDL is a specific chemoattractant for circulating human monocytes ${ }^{2}$ and oxidation of LDL at or near endothelial cells would result in monocyte binding. ${ }^{9}$ Subsequent vascular damage by o-LDL could assist monocyte transfer to the synovial intima. It has been proposed that the response to vascular injury may underlie the pathology of both atherosclerotic lesions ${ }^{10}$ and the inflamed synovium. ${ }^{1}$ Endothelial damage allows ready passage to neutrophils and plasma proteins such as IgG, which also becomes oxidatively modified and antigenic. ${ }^{11}$

A further observation reported here is the presence of o-LDL in fibrous tissue within the synovium. Again, a similar association has been noted in experimental atherosclerotic lesions. ${ }^{12}$ In this context, it is noteworthy that the macrophage scavenger receptor contains a collagen-like domain, and that o-LDL binds to collagen. ${ }^{13}$ Our early work in human atherosclerotic plaques suggested that LDL deposition in the environment of fibroblasts stimulated connective tissue formation and that this tended to be abnormal. ${ }^{14}$

We have recently developed an oxygen radical driven model of inflammation in the rat knee joint, inflamed synovial tissue from which has also shown the presence of foam cells, suggesting that it might be profitable to screen anti-atherosclerotic drugs in this model of synovitis. ${ }^{15}$

1 Rothschild B M, Masi A T. Pathogenesis of rheumatoid arthritis: a vascular hypothesis. Semin Arthritis Rheum 1992; 12: 11-31.

2 Steinberg D, Parthasarathy S, Carew T E, Khoo J C Witztum J L. Beyond cholesterol: modifications of low density lipoprotein that increase its artherogenicity. $N$ Engl f Med 1989; 320:915-24.

3 Brown M S, Goldstein J L. Lipoprotein metabolism in the macrophage: implications for cholesterol deposition in atherosclerosis. Ann Rev Biochem 1983; 52: 223-61.

4 Yla-Herttuala S, Rosenfeld M E, Parthasarathy S, et al. Gene expression in macrophage-rich human atherosclerotic lesions. 15-L ipoxygenase and acetyl low density lipoprotein receptor messenger RNA colocalize with lipoprein receptor messenger RNA colocalize with 1991; 87: 1146-52.

5 Selley M L, Bourne D J, Bartlett M R, et al. Occurrence of (E)-4-hydroxy-2-nonenal in plasma and synovial fluid of patients with rheumatoid arthritis and osteoarthritis. Ann Rheum Dis 1992; 51: 481-4.

6 Trenam C W, Winyard P G, Morris C J, Blake D R. Ironpromoted oxidative damage in rheumatic diseases. In Lauffer R B, ed. Iron and human diseases. Boca Raton: CRC Press, 1992: 395-417.

7 Fairburn K, Grootveld M, Ward R J, et al. $\alpha$-Tocopherol lipids and lipoproteins in knee-joint synovial fluid and serum from patients with inflammatory joint disease. Clin Sci 1993; 83: 657-64.

8 Esterbauer H, Dieber-Rotheneder M, Waeg G, Striegl G Jurgens G. Biochemical, structural, and functiona properties of oxidised low-density lipoprotein. Chem Res Toxicol 1990; 3: 77-92.

9 Berliner J A, Territo M C, Sevanian A, et al. Minimally modified low density lipoprotein stimulates monocyt endothelial cell interactions. $\mathcal{f}$ Clin Invest 1990; 85: 1260-6.

10 Ross R, Glomset J A. The pathogenesis of atherosclerosis N Engl f Med 1976; 295: 369-77.

11 Lunec J, Blake D R, McCleary S J, Brailsford S Bacon P A. Self-perpetuating mechanisms of immunoglobulin $G$ aggregation in rheumatoid inflammation. globulin $G$ aggregation in rhest 1985; 76: 2084-90.

12 Rosenfeld M E, Palinski W, Henttuala S Y, Butler S, Witztum J L. Distribution of oxidation specific lipidprotein adducts and apolipoprotein B in atherosclerotic lesions of varying severity from WHHL rabbits. Arteriosclerosis 1990; 10: 336-49.

13 Kalant N, McCormick S, Parniak M A. Effects of coppe and histidine on oxidative modification of low density lipoprotein and its subsequent binding to collagen. Arteriosclerosis and Thrombosis 1991; 11: 1322-9.

14 Morris C J, Bradby G V H, Walton K W. Fibrous longspacing collagen in human atherosclerosis. Atherosclerosis 1978; 31: 345-54.

15 Dabbagh A J, Blake D R, Morris C J. Development of an in vivo $\mathrm{H}_{2} \mathrm{O}_{2}$-initiated model of joint inflammation histological and systemic studies. Int $\mathcal{f}$ Exp Pathol. In press. 